\title{
Tough decoy targeting of predominant let-7 miRNA species in adult human hematopoietic cells
}

Jaira F. de Vasconcellos, Colleen Byrnes, Y. Terry Lee, Joshua M. Allwardt, Megha Kaushal, Antoinette Rabel and Jeffery L. Miller

\begin{abstract}
Background: In humans, the heterochronic cascade composed of the RNA-binding protein LIN28 and its major target, the let-7 family of microRNAs (miRNAs), is highly regulated during human erythroid ontogeny. Additionally, downregulation of the let-7 miRNAs in cultured adult CD34(+) cells or the over-expression of LIN28 in cultured erythrocytes from pediatric patients with HbSS genotype causes increased levels of fetal hemoglobin ( $\mathrm{HbF}$ ) in the range of 19-40\% of the total. Therefore, we hypothesized that focused targeting of individual let-7 miRNA family members would exhibit regulatory effect on $\mathrm{HbF}$ expression in human adult erythroblasts.
\end{abstract}

Methods: The expression levels of mature let-7 family members were measured by RT-qPCR in purified cell populations sorted from peripheral blood. To study the effects of let-7 miRNAs upon globin expression, a lentiviral construct that incorporated the tough decoy (TuD) design to target let-7a or let-7b was compared with empty vector controls. Transductions were performed in CD34(+) cells from adult healthy volunteers cultivated ex vivo in erythropoietinsupplemented serum-free media for 21 days. Downstream analyses included RT-qPCR, Western blot and HPLC for the characterization of adult and fetal hemoglobins.

Results: The expression of individual let-7 miRNA family members in adult peripheral blood cell populations demonstrated that let-7 $a$ and let-7b miRNAs are expressed at much higher levels than the other let-7 family members in purified adult human blood cell subsets with expression being predominantly in reticulocytes. Therefore, we focused this study upon the targeted inhibition of let-7a and let-7b with the TuD design to explore its effects upon developmentally-timed erythroid genes. Let-7a-TuD transductions significantly increased gamma-globin mRNA expression and $\mathrm{HbF}$ to an average of 38\%. Let-7a-TuD also significantly decreased the mRNA expression of some ontogeny-regulated erythroid genes, namely CA1 and GCNT2. In addition, the erythroid-related transcription factors BCL11A and HMGA2 were down- and up-regulated, respectively, by let-7a-TuD, while ZBTB7A, KLF1 and SOX6 remained unchanged.

Conclusions: Overall, our data demonstrate that let-7 miRNAs are differentially expressed in human hematopoietic cells, and that targeted inhibition of the highly-expressed species of this family is sufficient for developmentally-specific changes in gamma-globin expression and HbF levels.

Keywords: let-7, miRNAs, let-7a, let-7b, Gamma-globin, Fetal hemoglobin, HbF

\footnotetext{
*Correspondence: jm7f@nih.gov

Molecular Genomics and Therapeutics Section, Genetics of Development

and Disease Branch, National Institute of Diabetes and Digestive

and Kidney Diseases, National Institutes of Health, 10 Center Drive,

Building 10, Room 9N311, Bethesda, MD 20892, USA
} 


\section{Background}

MicroRNAs (miRNAs) are small (mostly 18-21 nucleotides long), non-coding RNAs, highly conserved across evolution and involved in the regulation of messenger RNAs (mRNAs). Intracellular miRNAs cause post-transcriptional repression of multiple mRNAs to which they bind [1]. The let-7 family of miRNAs in humans consists of twelve genes that encode nine mature miRNAs (let$7 a$, let-7b, let-7c, let-7d, let-7e, let-7f, let-7g, let-7i and miR-98). The expression of mature let-7 miRNAs can be regulated at the transcriptional and post-transcriptional levels, where post-transcriptional repression of let-7 (at both pri-let-7 and pre-let-7 stages) is mainly mediated by the RNA-binding protein LIN28 [2]. Two human homologs of the C. elegans lin 28 gene were identified and named LIN28A and LIN28B [3]. Interestingly, LIN28 proteins and their let-7 miRNA targets have several reported functions including regulation of developmental timing [4-7], stem cell pluripotency, and differentiation of skeletal muscle $[8,9]$.

In humans, reticulocyte levels of let-7 miRNAs increase with the fetal-to-adult developmental transition [10]. LIN28B expression is silenced during the same developmental switch. Transgenic increases of LIN28 proteins in adult erythroblasts, which as a consequence down-regulate the let-7 miRNAs, cause the cells to manifest fetal-like features [11, 12]. Augmented expression of $L I N 28 A / B$ also precipitated a rise in fetal hemoglobin ( $\mathrm{HbF})$ levels and amelioration of the sickling morphologies of enucleated erythrocytes cultured in vitro from pediatric patients with sickle cell disease (HbSS genotype) $[11,12]$. Earlier efforts aimed toward the reduced expression of let-7 by "sponge" targeting of the miRNA family seed region [11] resulted in mild $\mathrm{HbF}$ increases compared with LIN28 over-expression in the same cells [11]. Therefore, it remained inconclusive whether suppression of the let-7 family, or targeting of individual let-7 species are sufficient to cause the robust developmentally-specific changes in cellular phenotype that were manifested by LIN28 [11].

Here we investigate the expression levels of the individual let-7 miRNAs in human blood cells, and further explore the role of let-7 miRNAs upon ontogeny-related gene expression in the erythroid lineage. Expression of individual let-7 miRNA family members was quantitated in human peripheral blood cell populations, allowing a more focused strategy for reducing let-7 levels in the adult erythroblasts. Finally, lentiviruses designed specifically for let-7a and let-7b miRNA targeting were transduced in erythroblasts and explored for their regulation of $\mathrm{HbF}$ and other developmentally-regulated genes.

\section{Methods}

Ethics statement

Written informed consent was obtained from all research subjects prior to participation in this study. Approval for the research protocol and consent documents using primary erythroblasts and peripheral blood samples was granted by the Intramural National Institute of Diabetes and Digestive and Kidney Diseases Institutional Review Board.

\section{miRBase}

Mature let-7 miRNAs sequences were obtained from the miRBase database release 21 (http://mirbase.org). Details of the miRBase database have been previously described [13-17].

\section{Peripheral blood samples}

Peripheral blood cells were isolated using Ficoll-Paque Premium (GE Healthcare, Pittsburgh, PA) following manufacturer's instructions. Fresh post-ficoll peripheral blood cells were used for cell sorting based on forward and side scatter using the BD FACSAria I flow cytometer (BD Biosciences, San Jose, CA). Lymphocytes and monocytes were sorted from the post-ficoll interface. Neutrophils were obtained from the post-ficoll packed red cells, after lysis with ACK lysing buffer following manufacturer's protocol (Life Technologies, Grand Island, NY) and sorted based on forward and side scatter. Reticulocytes were obtained after filtration through a Purecell Neonatal High Efficiency Leukocyte Reduction Filter (PALL, Port Washington, NY) of the post-ficoll packed red cells. RNA from lymphocytes, monocytes and neutrophils was extracted using miRNeasy mini kit with QIAzol (Qiagen, Germantown, MD) and RNA from reticulocytes was extracted using Trizol LS following manufacturer's instructions (Thermo Fisher Scientific, Grand Island, NY).

\section{Cell culture}

Cryopreserved healthy adult human CD34(+) cells were cultured ex vivo in a 3-week serum-free system consisting of three phases (phase I: days 0-7, phase II: days 7-14 and phase III: days 14-21) as previously described [11, $18]$.

\section{Recombinant viral transduction}

Lentiviral particles with tough decoy (TuD) design [19], constructed to inhibit human let- $7 a$ or let-7b miRNAs (catalog numbers: HLTUD0001 and HLTUD0007, respectively) and negative vector control (HLTUD001C) were purchased from Sigma Aldrich (St. Louis, MO). A lentivirus shRNA vector to knockdown 
BCL11A (clone TRCN0000033449) and the respective lentiviral control (SHC002V) were also acquired from Sigma Aldrich. On culture day 3 of phase I, CD34(+) cells were transduced with the following lentiviral particles: let-7a-TuD, let-7b-TuD, BCL11A knockdown and each respective negative vector control (MOI of 6). After $24 \mathrm{~h}$, puromycin (Sigma Aldrich) was added to the culture. On culture day 7, cells were transferred to phase II medium containing EPO and cultivated at the conditions previously described without puromycin [18].

\section{Cell counts and cell morphology analyses}

Cell counts were performed throughout the culture period in a Z1 Coulter Particle Counter (Beckman Coulter, Indianapolis, IN) following manufacturer's instructions. Cell morphology was analyzed with the preparation of cytospins followed by Wright-Giemsa staining. Briefly, cytospins were prepared by centrifugation of the cytoslides using the Shandon Cytospin 4 (Thermo Fisher Scientific) at $1000 \mathrm{rpm}$ for $2 \mathrm{~min}$. Cytoslides were stained with Wright-Giemsa (Sigma-Aldrich, St. Louis, MO) for $50 \mathrm{~s}$ followed by two 1-min washes in distilled water.

\section{Flow cytometry analyses}

Erythroid differentiation was assessed with antibodies directed against CD71 and glycophorin A (Invitrogen, Carlsbad, CA) on culture days 14 and 21 using the BD FACSAria I flow cytometer (BD Biosciences) as previously described [20]. Enucleation was quantitated by thiazole orange (TO) staining (Sigma) on culture day 21. Fetal hemoglobin distribution was assessed with antibody directed against fetal hemoglobin (Life Technologies) at culture day 21 as previously described [21].

\section{Quantitative PCR for mRNAs}

Total RNA was isolated using miRNeasy mini kit with QIAzol (Qiagen) following manufacturer's instructions and complementary DNA (cDNA) was synthesized using SuperScript III reverse transcriptase (Thermo Fisher) following manufacturer's instructions as previously described [22, 23]. RT-qPCR assays and conditions were performed as previously described [11, 22-25]. Assayon-Demand Gene Expression Product (Thermo Fisher Scientific/Applied Biosystems) were used as follows: CA1 (Hs01100176_m1), GCNT2 (Hs00377334_m1), BCL11A (Hs00256254_m1), HMGA2 (Hs00971724_m1), ZBTB7A (Hs00792219_m1), KLF1 (Hs00610592_m1), SOX6 (Hs00264525_m1), LIN28A (Hs04189307_g1), and LIN28B (Hs01013729_m1). Absolute quantification for each target mRNA was determined by comparison with a standard curve that was run in parallel with biological samples as previously described [23]. Reactions were performed in triplicate.

\section{Quantitative PCR analysis for the let-7 family of miRNAs} Complementary DNA and real-time PCR reaction using Taqman microRNA assay (Applied Biosystems, Grand Island, NY) were performed as previously described [10, 22] for let-7a, let-7b, let-7c, let-7d, let-7e, let-7f, let-7g, let-7i and miR-98. Absolute quantification for each target miRNA was determined by comparison with a standard curve that was run in parallel with biological samples as previously described [22]. Standard curves were prepared on the basis of the synthetic targeted mature miRNA oligonucleotide of known concentration (at least five 1:10 serial dilutions) as previously described [22]. Reactions were performed in triplicate. A representative standard curve and its correspondent amplification plot for each let-7 miRNA family member is shown in Additional file 1.

\section{Western blot analyses}

Nuclear and cytoplasmic extracts from culture day 14 erythroblasts were prepared using the NE-PER Nuclear and Cytoplasmic Extraction kit (Pierce Biotechnology, Rockford, IL) as previously described [11]. Western blot protocols and conditions were performed as previously described [11]. Blots were probed with antibodies against CA1 (Abcam, Cambridge, MA), GCNT2 (Santa Cruz Biotechnology, Dallas, TX), BCL11A (Abcam), HMGA2 (GeneTex, Irvine, CA), ZBTB7A (Abcam), KLF1 (Abcam) and SOX6 (Santa Cruz Biotechnology). Histone H3, Lamin B1 or Beta-Actin (all from Abcam) were used as loading controls.

\section{Colony formation assay}

CD34(+) cells from three independent donors were transduced with let-7a tough decoy vector (catalog number: HLTUD0001, Sigma) or negative vector control (catalog number: HLTUD001C, Sigma) overnight and then mixed in MethoCult H4034 Optimum media (Stem Cell Technologies, Vancouver, Canada) supplemented with puromycin for colony formation assay with duplicate wells following manufacturer's protocol as previously described [18]. Colonies of erythroid progenitors (BFU-E and CFU-E), granulocyte-macrophage progenitors (CFU-GM, CFU-G and CFU-M) and multipotential granulocyte, erythroid, macrophage, megakaryocyte progenitors (CFU-GEMM) were counted for each donor and condition on culture day 14 .

\section{HPLC for adult and fetal hemoglobins}

Samples for HPLC analysis were prepared and analyzed as previously described $[23,26]$.

\section{Statistical analysis}

Replicates are expressed as mean \pm SD values and significance was calculated by two-tailed Student's t-test. 


\section{Results}

Reticulocytes contain higher total levels of mature let-7 miRNAs than other peripheral blood cell populations

The mature sequences of let-7 miRNA family members are defined and well-conserved across multiple species. As shown in Additional file 2, let-7a is the most well-conserved family member across evolution. The alignment and nucleotide differences of the human mature let-7 family members in comparison to the human mature let$7 a$ miRNA is shown in Fig. 1 (sequences were obtained on miRBase, http://mirbase.org/, Release 21). Following the in silico comparison of the let-7 miRNAs sequences, we explored the expression levels of mature let-7a and the related miRNA family members in purified mononuclear cell populations and reticulocytes from peripheral blood. Interestingly, reticulocytes have higher levels of total let7 miRNAs compared to monocytes, lymphocytes, and neutrophils (Fig. 2; monocytes: $3.5 \mathrm{E}+06 \pm 2.7 \mathrm{E}+06$ copies/ng; lymphocytes: $1.1 \mathrm{E}+07 \pm 6.2 \mathrm{E}+06$ copies/ng; neutrophils: $2.0 \mathrm{E}+07 \pm 1.1 \mathrm{E}+07$ copies/ng and reticulocytes: $1.7 \mathrm{E}+08 \pm 1.0 \mathrm{E}+08$ copies $/ \mathrm{ng}$ ). Unexpectedly, among the individual family members, let-7a and let-7b were identified as the predominant members of the let7 family in peripheral blood cell populations. Hence, we became more interested in the effects of focused reductions of these highly-expressed species, let-7a and let-7b, in erythroblasts.

\section{Studies of cell proliferation and differentiation showed decreased enucleation upon let-7 miRNAs focused inhibition in adult erythroblasts cultivated ex vivo}

To investigate the inhibition of let-7a and let-7b miRNAs, lentiviral constructs that incorporated the Tough Decoy $(\mathrm{TuD})$ design targeting let $-7 a$ or let $-7 b$ were compared with control vector. Transductions were performed in CD34(+) cells from adult healthy volunteers cultivated ex vivo in erythropoietin-supplemented serum-free media for 21 days. The effects of miRNA inhibition by $\mathrm{TuD}$ vectors has been shown to

\footnotetext{
hsa-let-7a-5p UGAGGUAGUAGGUUGUAUAGUU hsa-let-7b-5p UGAGGUAGUAGGUUGUGUGGUU hsa-let-7c-5p UGAGGUAGUAGGUUGUAUGGUU hsa-let-7d-5p AGAGGUAGUAGGUUGCAUAGUU hsa-let-7e-5p UGAGGUAGGAGGUUGUAUAGUU hsa-let-7f-5p UGAGGUAGUAGAUUGUAUAGUU hsa-let-7g-5p UGAGGUAGUAGUUUGUACAGUU hsa-let-7i-5p UGAGGUAGUAGUUUGUGCUGUU hsa-miR-98-5p UGAGGUAGUAAGUUGUAUUGUU

Fig. 1 The human let-7 family of miRNAs. The nucleotide differences of the human mature let-7 family members in comparison to the

human mature let-7a miRNA are marked in red font. Sequences were obtained using miRBase (http://mirbase.org/), Release 21
}

be accompanied by a decrease of target miRNA levels [27], as a result of target-miRNA sequestration [27, 28] and degradation, the latter via the 'tailing and trimming' pathway [28]. As shown in Fig. 3a, b, inhibition of let-7 miRNAs by TuD caused reduction in the levels of let-7 species as assessed by RT-qPCR at culture day 14 (let7a RT-qPCR: control: $1.4 \mathrm{E}+07 \pm 2.4 \mathrm{E}+06$ copies/ng, let-7a-TuD: $1.6 \mathrm{E}+06 \pm 4.6 \mathrm{E}+05$ copies/ng, $\mathrm{p}=0.0003$; let-7b RT-qPCR: control: $1.0 \mathrm{E}+07 \pm 4.9 \mathrm{E}+05$, let-7bTuD: $1.6 \mathrm{E}+06 \pm 5.1 \mathrm{E}+05, \mathrm{p}=0.00002)$. Importantly, both let-7a-TuD and let-7b-TuD reduced the expression of both let-7a and let-7b miRNAs, demonstrating a more focused, but not exclusive targeting of miRNA by this technology. When the total levels of let-7 miRNAs were compared between let-7a-TuD and let-7b-TuD designs, the let-7a-TuD vector was more efficient in reducing the total levels of let-7 miRNAs compared to let-7bTuD (Fig. 3c; $88 \%$ versus $75 \%$ suppression of total let-7 miRNA levels after let-7a-TuD and let-7b-TuD transductions, respectively). Since the data suggested that let-7a$\mathrm{TuD}$ resulted in a greater reduction in total levels of let-7 miRNAs compared to let-7b-TuD, the let-7a-TuD vector was utilized for subsequent studies.

Cell proliferation and erythroblast differentiation were compared between control transductions and let-7a-TuD. Similar cell counts were observed between let-7a-TuD versus control transductions at culture days 14 and 21 of differentiation (Day 14: control: $2.81 \mathrm{E}+06 \pm 6.24 \mathrm{E}+05$ cells $/ \mathrm{mL}$, let-7a-TuD: $3.06 \mathrm{E}+06 \pm 7.77 \mathrm{E}+05$ cells $/ \mathrm{mL}, \mathrm{p}=0.31$, Fig. $4 \mathrm{a}$; Day 21: control: $1.32 \mathrm{E}+06 \pm 3.15 \mathrm{E}+05$ cells $/ \mathrm{mL}$, let7a-TuD: $1.10 \mathrm{E}+06 \pm 2.98 \mathrm{E}+05$ cells $/ \mathrm{mL}, \mathrm{p}=0.18$, Fig. 4b). In addition, let-7a-TuD cells were morphologically comparable to control transductions at culture day 21 (Fig. 4c). To investigate the effects of the let-7a$\mathrm{TuD}$ vector on the survival and ability of the CD34(+) cells to grow into colonies, a colony formation assay was performed. As shown in Fig. 4d, no differences were observed on the number of puromycin-resistant colonies of BFU-E, CFU-GM, CFU-E, CFU-M, CFUGEMM and CFU-G progenitors on let-7a-TuD samples compared to control transductions.

Flow cytometry analysis of transferrin receptor (CD71) and glycophorin A (GPA) were performed at culture days 14 and 21. As shown in Fig. 5a and Additional file 3A-D, erythroblast differentiation (CD71 and GPA) was not affected by let-7a-TuD. Thiazole orange staining on culture day 21 showed that both let-7a-TuD and control transductions achieved enucleation, however, there was a significant decrease in the percent of enucleated cells in let-7a-TuD compared to control transductions (control: $45.4 \pm 7.0 \%$, let-7a-TuD: $30.7 \pm 3.9 \%, \mathrm{p}=0.01$; Fig. $5 \mathrm{~b}$ and Additional file $3 \mathrm{E}$ ). Finally, $\mathrm{HbF}$ distribution was 

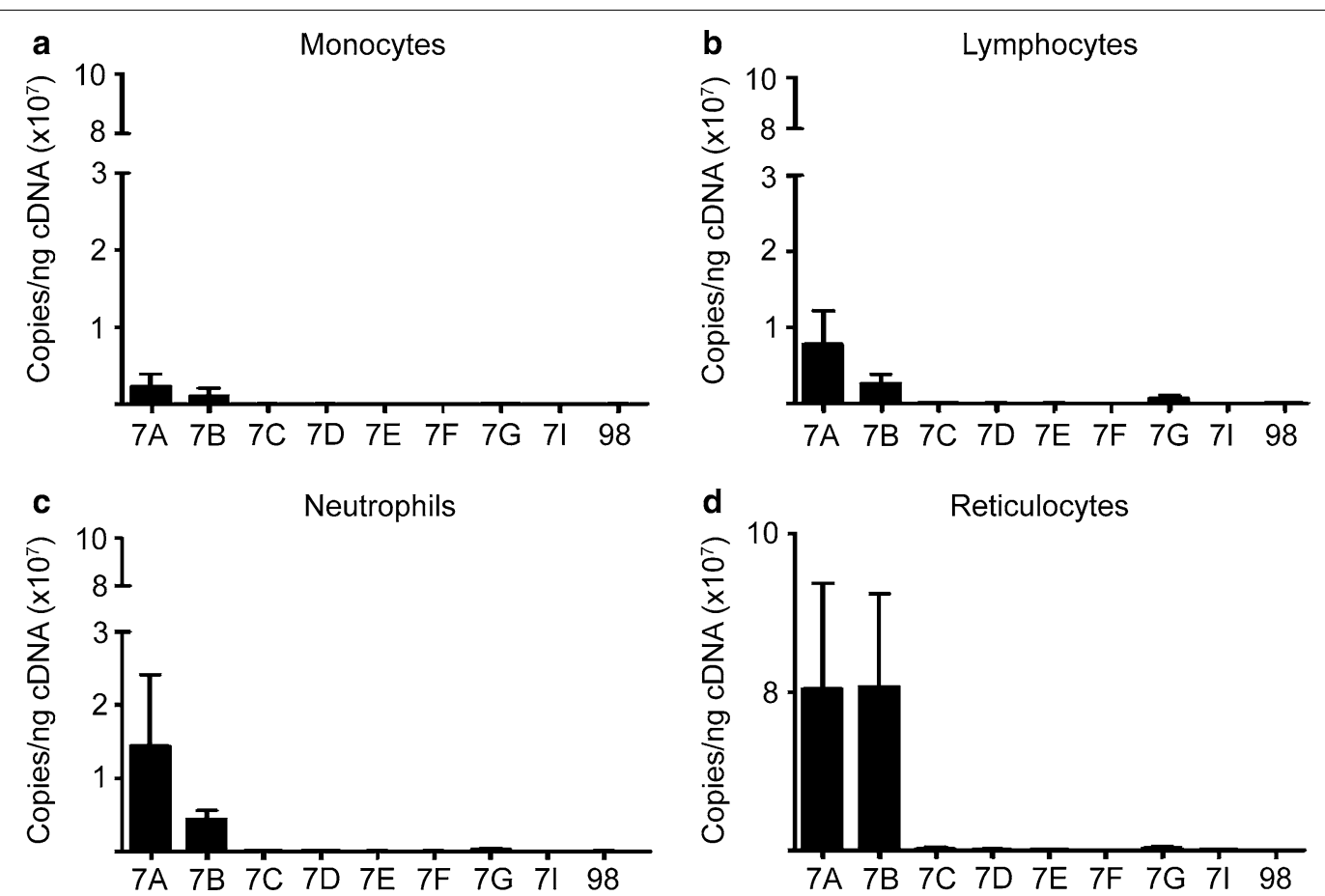

Fig. 2 Let-7a and let-7b are predominant miRNAs among the let-7 family members in peripheral blood cells. Levels of mature let-7 miRNAs in a monocytes $(n=4)$, b lymphocytes $(n=4)$, c neutrophils $(n=4)$ and $\mathbf{d}$ reticulocytes $(n=5)$. Samples were analyzed by RT-qPCR quantitation of copy number per nanogram of complementary DNA (cDNA) (copies/ng cDNA). Mean value \pm SD of independent donors for each condition

assessed by HbF staining at culture day 21. As shown in Fig. 5c, pancellular expression of $\mathrm{HbF}$ was observed upon let-7a-TuD compared to control transductions (control: $53.3 \pm 6.7$, let-7a-TuD: $85.4 \pm 4.7, \mathrm{p}=0.02$, Additional file 3F).

\section{Let-7a-TuD increases gamma-globin mRNA and fetal hemoglobin levels in cultured adult erythroblasts}

To further characterize the effects of cultured adult erythroblasts, RT-qPCR analysis of the globin genes was performed at culture day 14. No major differences were observed in alpha-, mu-, theta-, zeta-, beta-, delta- and epsilon-globin mRNA levels among let-7a-TuD samples compared to control transductions (Fig. 6a, b). However, the gamma-globin mRNA expression level was significantly increased in let-7a-TuD (control: $1.2 \mathrm{E}+06 \pm 6.8 \mathrm{E}+05$ copies/ng, let-7a-TuD: $1.1 \mathrm{E}+07 \pm 4.5 \mathrm{E}+06$ copies $/ \mathrm{ng}, \mathrm{p}=0.004$; Fig. $6 \mathrm{~b})$. In addition, hemoglobin profiles (HPLC) were generated at culture day 21 , showing a robust increase in $\mathrm{HbF}$ levels upon treatment with the TuD lentiviral vector (Fig. 6c, d; control: $4.7 \pm 0.6 \%$, let-7a-TuD: $38.2 \pm 3.8 \%$, $\mathrm{p}=0.00003$ ). For comparison purposes, HPLC analysis of let-7b-TuD was performed and demonstrated that let-7b-TuD caused less pronounced changes in the $\mathrm{HbF}$ levels, reaching $29.7 \pm 4.5 \%$ compared to control transductions at $4.1 \pm 0.9 \%$ in matched cultures.

\section{Let-7 miRNAs inhibition by TuD demonstrates additional developmentally-specific gene regulation in adult erythroblasts}

The fetal-to-adult transition in humans is accompanied by increased expression in the levels of carbonic anhydrase I (CA1), which after globin is the second most abundant protein in adult erythroid cells [29]. In addition, increased expression in the levels of glucosaminyl (N-acetyl) transferase 2 (GCNT2) during the fetal-toadult transition catalyzes the expression of adult blood group I antigen in erythrocytes [30, 31]. To investigate whether let-7a-TuD transduced cells would have effects on these erythroid-relevant developmentally regulated genes, let-7a-TuD cells and control transductions were investigated for the expression of CA1 and GCNT2 by RT-qPCR and Western blot. Interestingly, both $C A 1$ and GCNT2 were significantly down-regulated at the mRNA level in let-7a-TuD samples compared to controls (CA1: control: $3.3 . E+04 \pm 1.3 . E+04$ copies/ng; let-7a-TuD: 7.5.E $+03 \pm 6.9 . \mathrm{E}+03$ copies/ng; $\mathrm{p}=0.005 ;$ GCNT2: control: $3.8 . \mathrm{E}+03 \pm$ 7.7.E +02 copies/ng; let-7a-TuD: 2.2.E $+02 \pm$ 9.4.E $+01 ; p=0.002$; Fig. 6e, f). However, at 


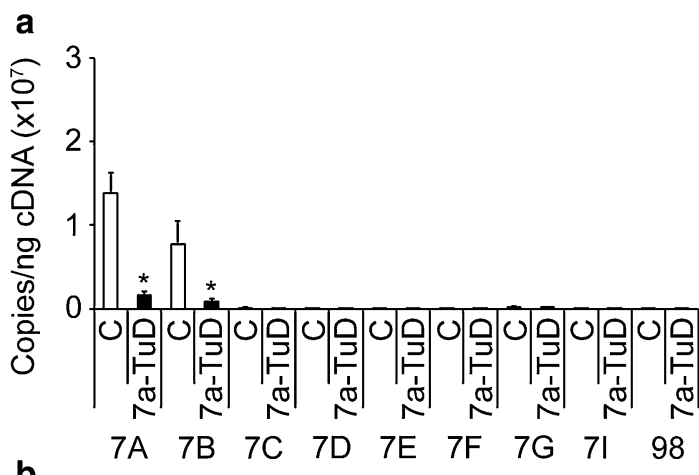

b
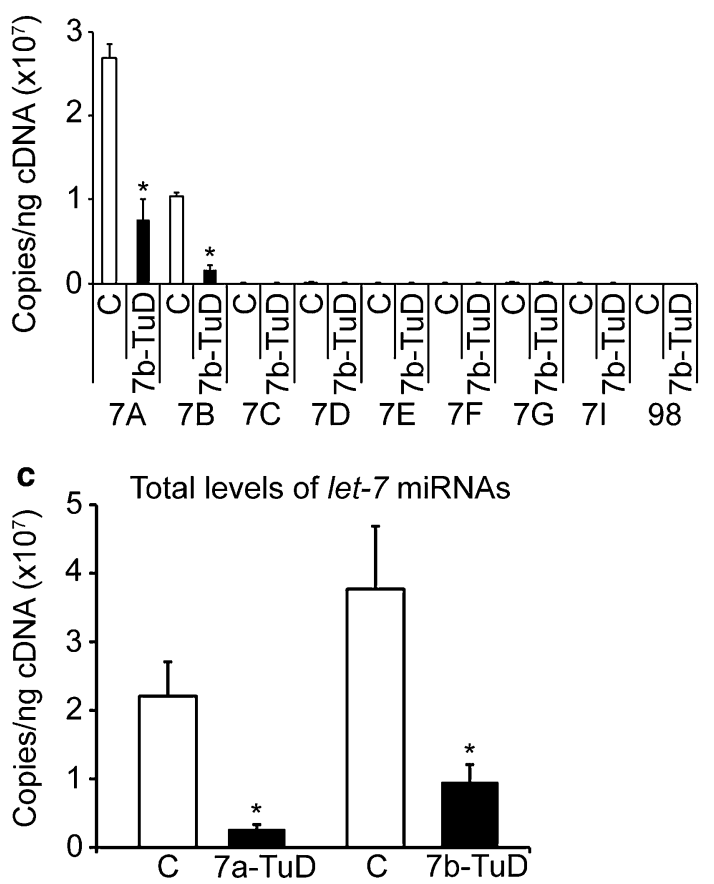

Fig. 3 Let-7 miRNAs focused inhibition by TuD is accompanied by the reduction of mature let-7 levels. Quantitation of copy number per nanogram cDNA (copies/ng cDNA) by RT-qPCR in a let-7a-TuD $(n=5)$ and $\mathbf{b}$ let-7b-TuD $(n=4)$, both compared to control transductions. c Total levels of mature let-7 miRNAs in let-7a-TuD and let-7bTuD treatments compared to control. Open bars represent control and black bars represent let-7a-TuD or let-7b-TuD. Mean value \pm SD of independent donors for each condition. $p$ values were calculated for comparison of control versus let-7a, let-7b or the total levels of let-7 miRNAs using two-tailed Student's t-test. TuD, tough decoy design; C, control (negative control vector) transduction; 7a-TuD, let-7a tough decoy design; $7 b-T u D$, let-7b tough decoy design. ${ }^{*} p<0.05$

the protein level, only CA1 was down-regulated in let7a-TuD samples compared to controls, while GCNT2 remained unchanged (Fig. 6g, h). Importantly, LIN28A and LIN28B mRNA transcripts remained at background levels and below the detection limits, respectively, in both let-7a-TuD and control transductions.
Additionally, the erythroid-related genes (BCL11A, HMGA2, ZBTB7A, KLF1 and SOX6) [22, 32-37] were studied for comparison in let-7a-TuD and control transductions. Interestingly, while BCL11A mRNA expression levels were significantly reduced in let$7 \mathrm{a}-\mathrm{TuD}$ samples compared to control transductions (control: $1.7 \mathrm{E}+03 \pm 4.5 \mathrm{E}+02$ copies/ng; let-7a-TuD: $4.3 \mathrm{E}+02 \pm 1.8 \mathrm{E}+02$ copies/ng; $\mathrm{p}=0.003$ ), no significant differences were observed in $H M G A 2, Z B T B 7 A$, KLF1 and SOX6 transcripts (Fig. 7a-e). However, marked reduction in the protein level of BCL11A was observed after let-7a-TuD (Fig. 7f), while HMGA2 showed a double-band pattern previously reported [38] with a marked increase in the intensity of the upper band after let-7aTuD (Fig. 7f). Of note, ZBTB7A, KLF1, and SOX6 protein levels demonstrated no consistent change with let-7a-TuD.

\section{Direct knockdown of $B C L 11 A$ does not significantly affect the let-7 family of miRNAs}

Finally, to determine whether direct down-regulation of $B C L 11 A$ would affect the let-7 family of miRNAs, primary CD34(+) cells were transduced in this experimental system with a lentivirus shRNA vector to knockdown $B C L 11 A$ as well as the lentiviral vector matched control for comparison. BCL11A knockdown (BCL11A-KD) was confirmed by RT-qPCR (Fig. 8a). Interestingly, BCL11AKD did not significantly affect the let-7 family of miRNAs (Fig. 8b), which suggests that the let-7 miRNAs are upstream regulators of BCL11A.

\section{Discussion}

In this study, we show that the let-7 family of miRNAs is differentially expressed in purified adult human blood, and that let-7a and let-7b are the predominantly expressed family members in the analyzed peripheral blood cell populations, including reticulocytes. Focused suppression of let-7a and let-7b miRNAs with a miRNA Tough Decoy approach in erythroblasts was sufficient to cause robust changes in several developmentally-specific erythroblast genes including increases in gamma-globin mRNA expression and $\mathrm{HbF}$ to reach mean levels around $35-40 \%$ of the total hemoglobin produced. As such, these data confirm a functional role for erythroblast let-7 miRNAs in globin gene regulation and suggest that targeted reductions of the predominant let-7s should be further explored for application in patients with sickle cell disease and beta-hemoglobin disorders.

The first description of small-RNAs as regulators of developmental timing events was observed in studies of C. elegans, when lin-4 and, subsequently let-7 (from the initial denomination lethal-7) [39-41] were identified. 

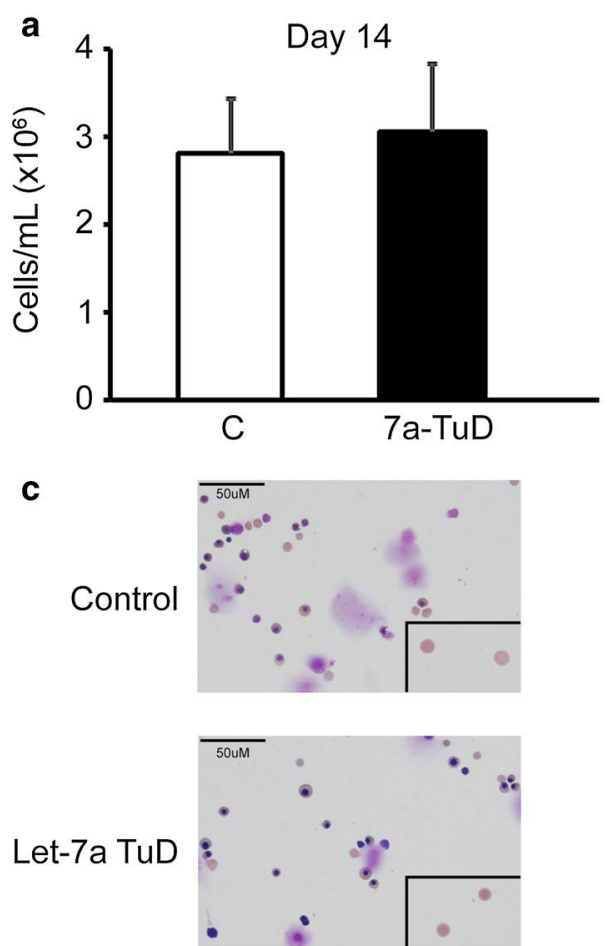
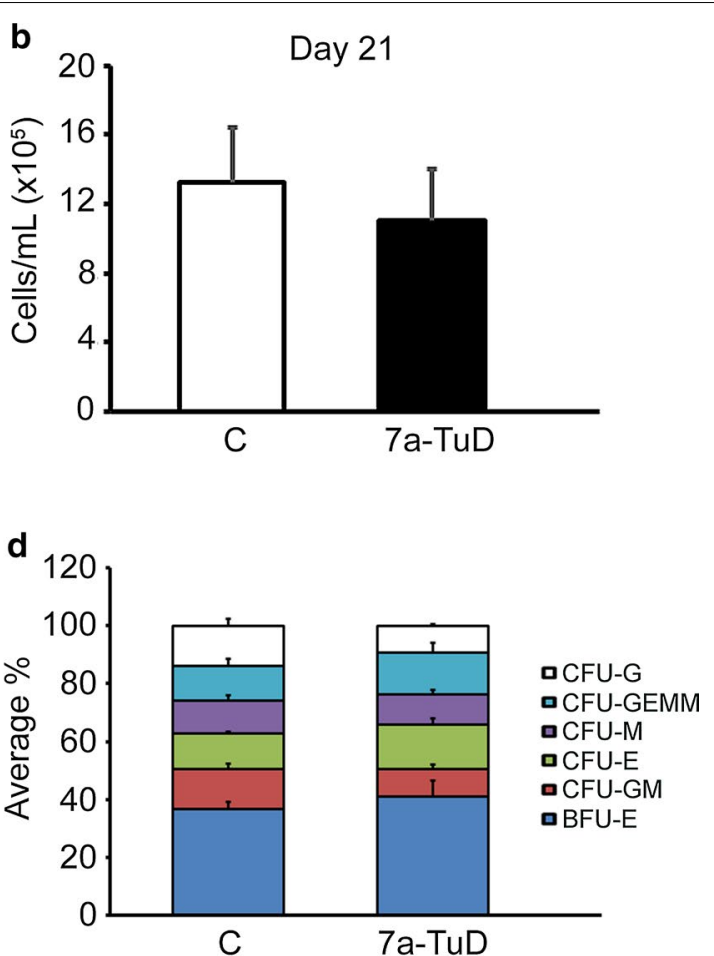

Fig. 4 Let-7 miRNAs focused inhibition by TuD demonstrates comparable levels of cell proliferation and equivalent cell morphology compared to control transductions. Cell proliferation was assessed by cell counts (cells/mL) performed at cultures a day 14 and b day 21 . Open bars represent control and black bars represent let-7a-TuD. Mean value \pm SD of five independent donors for each condition. Cell morphology was analyzed at culture day 21 with the preparation of cytospins followed by Wright-Giemsa staining. Representative images are shown from c control transduction and let-7a-TuD with enucleated cells (inset). d Colony formation assay was performed in control transduction and let-7a-TuD at culture day 14. Cells were transduced with lentivirus particles and cultured in semi-solid methylcellulose medium supplemented with puromycin. Average colony counts were obtained from duplicate wells for each condition from three independent donors. Average percentage of each colony type is shown as separate colors (see color key on the right of the bar graph). C, control transduction; let-7a-TuD, let-7a tough decoy design

The mature let-7 miRNAs sequence and its function as a heterochronic regulator are highly conserved across evolution [42], and let-7a is the most well-conserved let-7 family member. Mature let-7a originated from three different genomic loci (let-7a-1, let-7a-2 and let-7a-3) and mature let- $7 f$ originated from miRNA precursors of two distinct genomic locations (let-7f-1 and let-7f-2), while all other family members are originated from one precursor miRNA sequence.

Also of interest, we observed that let-7a and let-7b are the major species detected by RT-qPCR in all peripheral blood cell populations analyzed. As reported previously, array-based analyses of the let-7 miRNAs demonstrated similarly high levels of each let-7 family member in human adult reticulocytes rather than the predominance of let-7a and let-7b [10]. The differences between these microarrays versus $\mathrm{RT}-\mathrm{qPCR}$ results may be due to a higher level of cross-reactivity in let-7 miRNAs arraybased detection [43].

Here we aimed our gene transduction studies to suppress the two most prevalent members of the let-7
miRNA family, let-7a and let-7b. Importantly, the high similarity among the mature let-7 miRNA sequences prevented the exclusive targeting by tough decoy $(\mathrm{TuD})$ lentiviral designs. While TuD inhibitors are able to provide a more focused inhibition of miRNAs than other strategies $[27,28]$, similar non-specificity of TuD constructs for targeted species in the same miRNA family was previously described [19]. These results support the notion that targeted let-7 inhibition is a robust approach towards the manipulation of $\mathrm{HbF}$ levels in adult erythroblasts. Genomic targeting of individual let-7 species, perhaps with short palindromic repeat technologies, may be useful for determination of individual let-7 family member effects upon $\mathrm{HbF}$.

Interestingly, the magnitude of total let-7 suppression was proportional to the increase in gamma-globin mRNA and $\mathrm{HbF}$ in studies reported to date. It is known that LIN28 proteins regulate let-7 biogenesis and that let-7 miRNAs regulate LIN28 levels by binding to its $3^{\prime}$ untranslated region in a double negative feedback loop [44]. The absence of increased LIN28A or LIN28B 


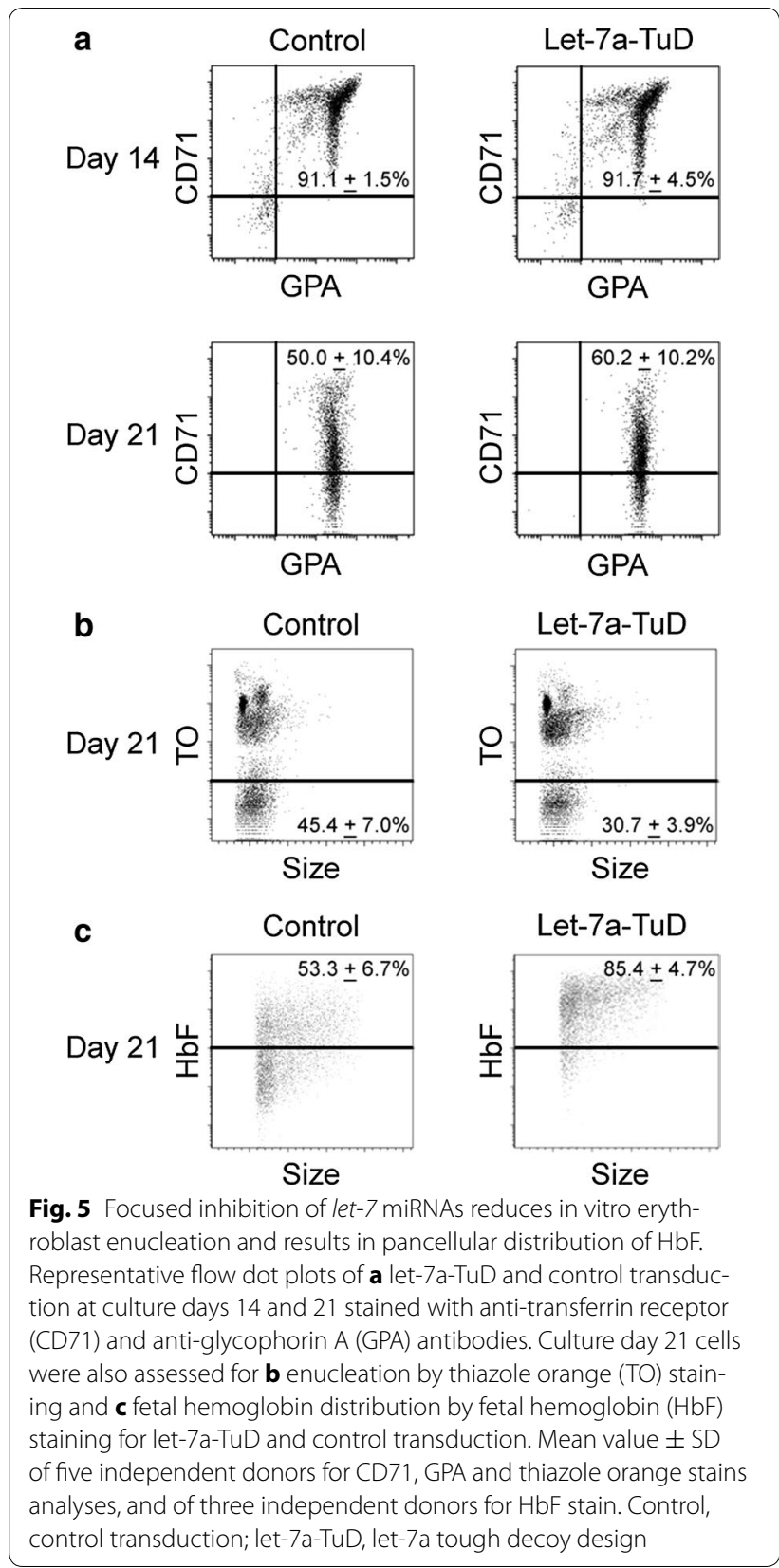

mRNA transcripts after let-7 suppression suggests that the LIN28 genes are transcriptionally silent rather than post-transcriptionally degraded by let-7 in the adult cells. Our study also provides the first evidence that the let-7 effects extend beyond globin gene regulation to include other markers of the fetal-to-adult switch in the erythroid lineage, namely $C A 1$ and GCNT2. Interestingly, reduced levels were observed only at the protein levels of CA1, while GCNT2 levels remained unchanged.
The biological significance of this finding will require further investigation.

The erythroid-related genes BCL11A, HMGA2, ZBTB7A, KLF1 and SOX6 were investigated upon let-7 suppression. The B-cell CLL/lymphoma 11A (BCL11A) is a zinc-finger transcription factor known to regulate gamma-globin and HbF levels in human erythroid cells [32] as well as to rescue the sickle cell disease phenotype in a murine model through the activation of $\mathrm{HbF}$ [33]. The High Mobility Group AT-hook 2 (HMGA2) is known as an architectural transcription factor and a target of the let-7 miRNAs [34] that has been recently reported to regulate gamma-globin mRNA and moderately increase $\mathrm{HbF}$ levels in human adult erythroblasts in vitro [22]. The Leukemia/Lymphoma-Related Factor (LRF) encoded by the Zinc Finger and BTB Domain Containing 7A (ZBTB7A) gene is also a zinc-finger transcription factor shown to cause robust increases in the $\mathrm{HbF}$ levels in human cultured erythroblasts [35]. The Kruppel like factor 1 (KLF1) is an erythroid-specific transcription factor known to regulate the expression of several erythroid genes including $B C L 11 A$ [36]. Finally, the SRY-box 6 (SOX6) is a transcription factor that contains a conserved DNA-binding domain and was demonstrated to physically interact and co-occupy the human beta-globin cluster with BCL11A and other transcription factors such as GATA1 [37]. Interestingly, marked modulations were observed only at BCL11A (down-regulation at both the mRNA and protein levels) and HMGA2 (up-regulation at the protein level).

Overall, we interpret our data as demonstrating that reduction of let-7, in the absence of other potential LIN28 effects, is a main driver of these developmentallyregulated genes in erythroblasts. While LIN28 effects upon the expression of $B C L 11 A$ have been inconsistent in prior studies $[11,12]$, this study shows that robust let-7 reduction is sufficient to reduce BCL11A as well as to increase HMGA2 for increased gamma-globin transcription. Future studies should be aimed toward understanding how this well-conserved miRNA family is able to regulate erythroid gene activity associated with the fetal-to-adult transition in humans. Since let-7 has a more generic role in timing worm development, such studies may ultimately demonstrate how the let- 7 developmental clock circuit functionally evolved in human tissues.

\section{Conclusions}

The let-7 family of miRNAs is differentially expressed among monocytes, lymphocytes, neutrophils, and reticulocytes from adult human blood and higher expression 

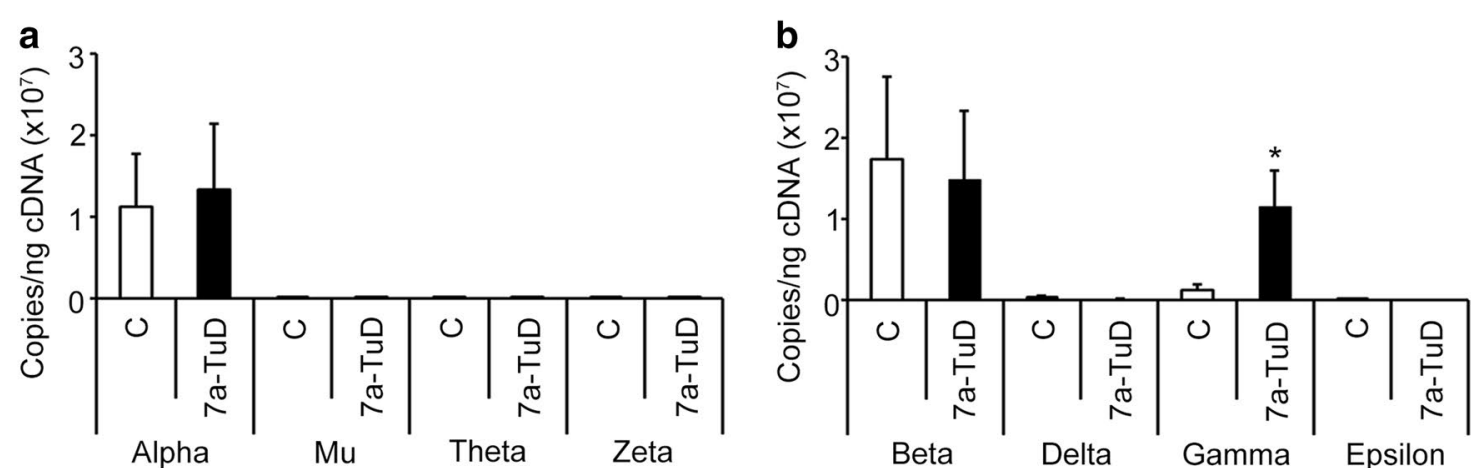

C

Control

Let-7a-TuD

d
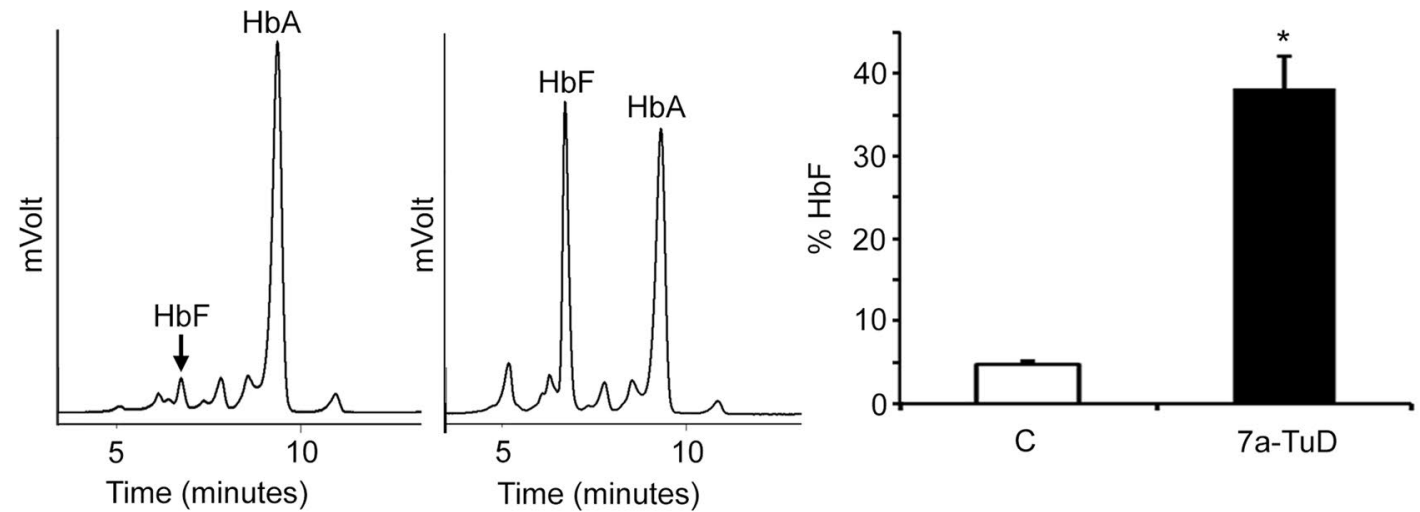

e

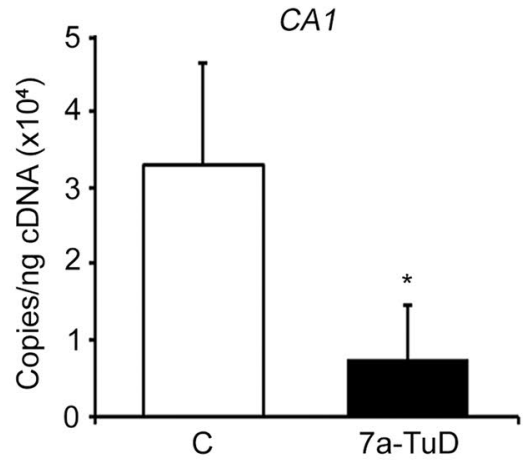

f

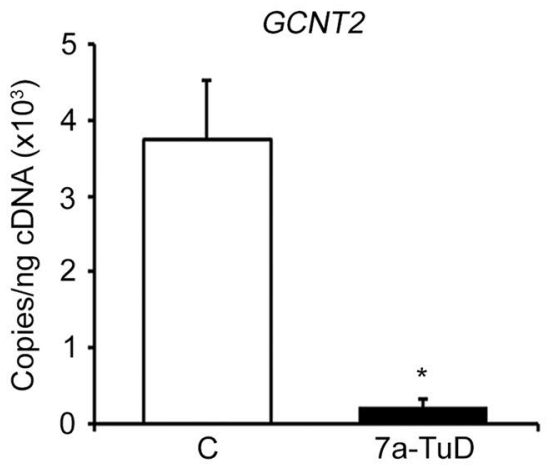

g

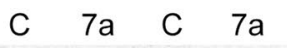

C 7
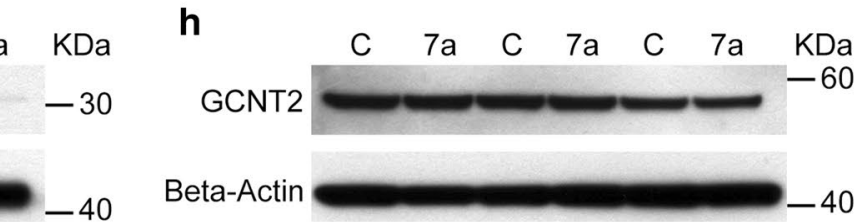

Fig. 6 Focused inhibition of let-7 miRNAs regulates gamma-globin and HbF levels in human erythroblasts ex vivo. Let-7a-TuD and control transductions were investigated for a alpha-, mu-, theta- and zeta-globins, and $\mathbf{b}$ beta-, delta-, gamma- and epsilon-globins. RT-qPCR analyses were performed at culture day 14. c Representative HPLC tracings. $\mathrm{HbF}$ and $\mathrm{HbA}$ peaks are labeled on each graph (y-axis, mVolts; $x$-axis, elution time in minutes). d HPLC analysis of hemoglobin from let-7a-TuD compared to control transductions. HPLC samples were collected at culture day 21. Let-7a-TuD effects in $\mathbf{e}$ CA1 and $\mathbf{f}$ GCNT2 mRNA levels. RT-qPCR analyses were performed at culture day 14. Open bars represent control and black bars represent let-7a-TuD. Mean value \pm SD of five independent donors for each condition. $p$ values were calculated using two-tailed Student's t-test. Western blot analyses of $\mathbf{g}$ CA1 and $\mathbf{h}$ GCNT2 in the cytoplasmic extracts of three independent donors at culture day 14 upon let-7a-TuD compared to control transductions. Blots were probed with anti-CA1 or anti-GCNT2 antibodies as indicated. Beta-Actin was used as loading control. C, control (negative control vector) transduction; 7a-TuD or 7a, let-7a tough decoy design. ${ }^{*} \mathrm{p}<0.05$ 

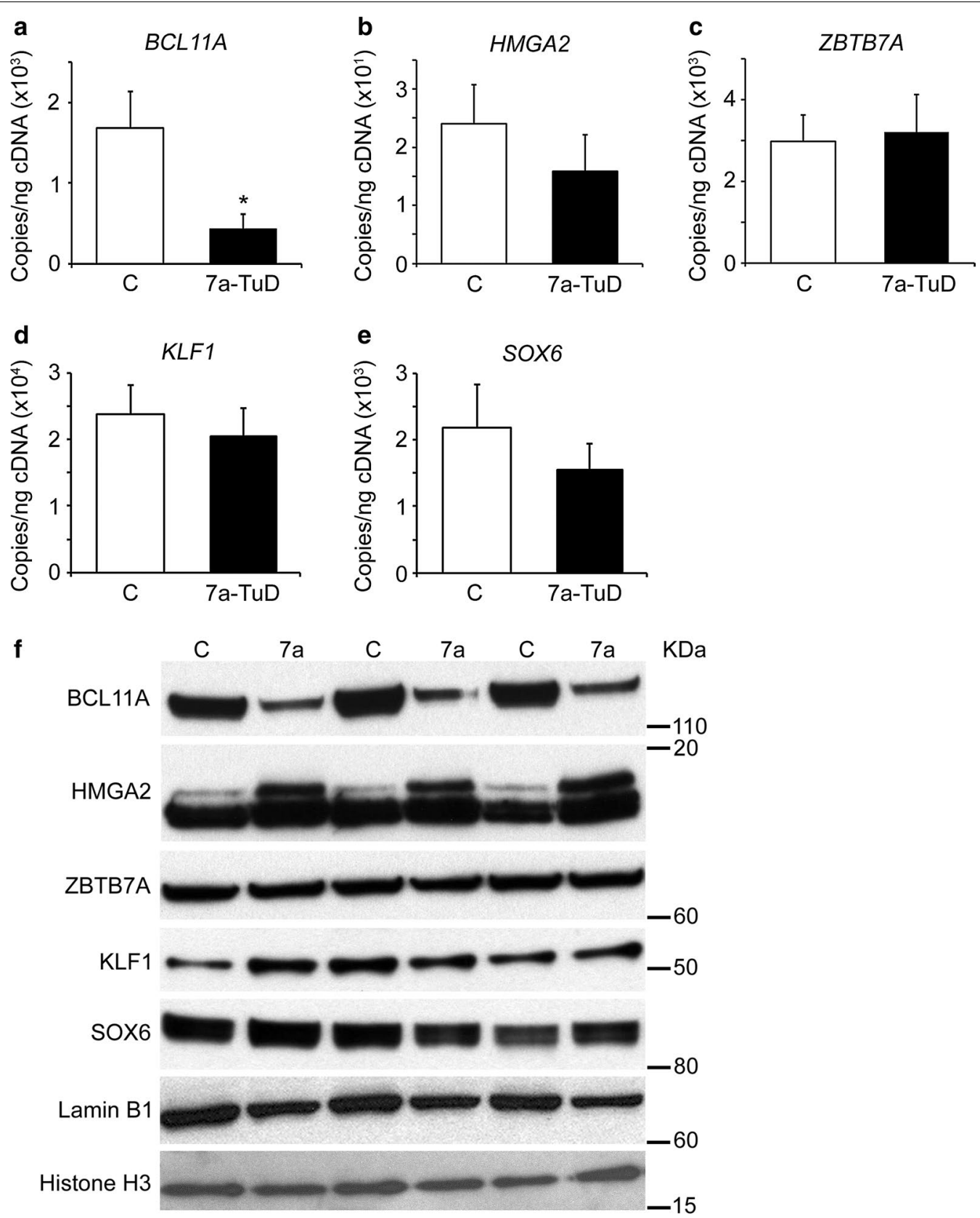

Fig. 7 Let-7 miRNAs focused inhibition modulates the expression levels of BCL11A and HMGA2. Let-7a-TuD effects in a BCL11A, b HMGA2, c ZBTB7A, d KLF1 and e SOX6 mRNA levels. RT-qPCR analyses were performed at culture day 14. Open bars represent control and black bars represent let-7aTuD. Mean value \pm SD of at least four independent donors for each condition. $p$ values were calculated using two-tailed Student's t-test. $\mathbf{f}$ Western blot analyses of BCL11A, HMGA2, ZBTB7A, KLF1 and SOX6 in the nuclear extracts of three independent donors at culture day 14 upon let-7a-TuD compared to control transductions. Blots were probed with anti-BCL11A, anti-HMGA2, anti-ZBTB7A, anti-KLF1 or anti-SOX6 antibodies as indicated. Lamin B1 and Histone H3 were used as loading controls. C, control (negative control vector) transduction; 7a-TuD or 7a, let-7a tough decoy design. ${ }^{*} p<0.05$ 


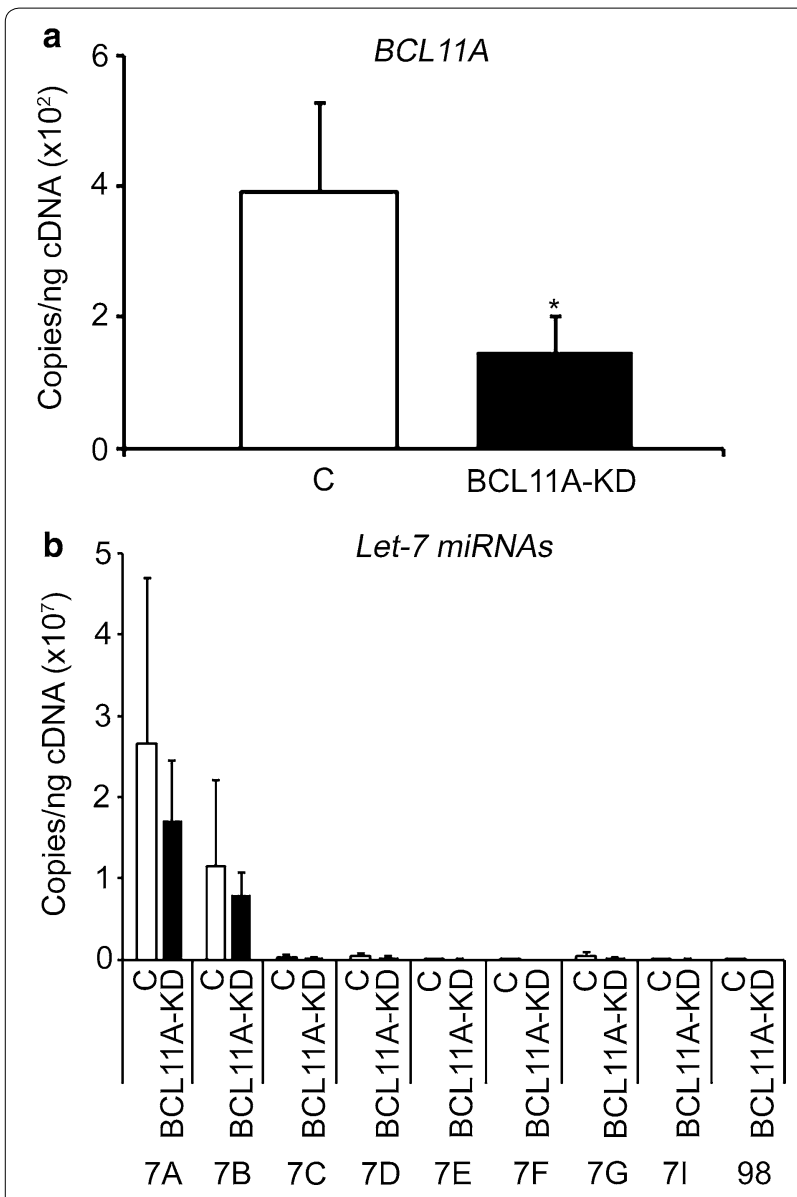

Fig. $8 B C L 11 A$ does not regulate the let-7 family of miRNAs. a $B C L 11 A$ knockdown (BCL11A-KD) was confirmed by RT-qPCR. b BCL11A$K D$ effects in the expression levels of the let-7 family of miRNAs. RT-qPCRs were performed at culture day 14. Open bars represent control and black bars represent BCL11A-KD. Mean value \pm SD of three independent donors for each condition. $p$ value was calculated using two-tailed Student's t-test. C, control (negative control vector) transduction; BCL11A-KD, BCL 11A knockdown. * $\mathrm{p}<0.05$

levels of the let-7 miRNAs were observed in reticulocytes. Remarkably, let-7a and let-7b are predominantly expressed species in all peripheral blood cell populations analyzed. Also of interest, targeted reduction of let-7a was more efficient than let-7b, and focused targeting of let-7a in erythroblasts is sufficient to cause robust increases in gamma-globin mRNA expression and $\mathrm{HbF}$ to mean levels around $38 \%$ of the total hemoglobin produced. Targeting of individual let-7 genes or additional RNA transcripts from the let-7 cascade may be useful for therapeutic induction of $\mathrm{HbF}$ levels in patients with sickle cell disease or other beta-hemoglobinopathies.

\section{Additional files}

\begin{abstract}
Additional file 1. Representative standard curve and amplification plot from each let-7 family member RT-qPCR. Standard curve and amplification plot from (A) let-7a, (B) let-7b, (C) let-7c, (D) let-7d, (E) let-7e, (F) let-7f, (G) let-7g, (H) let-7i and (I) miR-98. RT-qPCR quantitation of copy number per nanogram of complementary DNA (cDNA) (copies/ng cDNA). $\mathrm{Ct}=$ cycle threshold.
\end{abstract}

Additional file 2. Evolutionary conservation of the let-7 family of miRNAs from representative species progressing from the worm to human. Mature let-7 sequences from each species compared to the corresponding human sequence. Mature let-7 sequences from all species were obtained from the miRBase database release 21 (http://mirbase.org). Some members of the family may be missing due to incomplete sequencing, rather than their absence from a species.

Additional file 3. Quantitative analysis of the flow cytometric results measured by fluorescence-activated cell analysis of control transduction and let-7a-TuD. (A) Percentage of CD71(+) and GPA(+) cells or (B) CD71(+) and GPA(-) cells at culture day 14. (C) Percentage of CD71(+) and GPA(+) cells or (D) CD71(-) and GPA(+) cells at culture day 21. (E) Percentage of thiazole orange negative cells (enucleated) at culture day 21. (F) Percentage of fetal hemoglobin positive cells at culture day 21. Open bars represent control and black bars represent let-7a-TuD. Mean value \pm SD of five independent donors for CD71, GPA and thiazole orange stains. Mean value \pm SD of three independent donors for $\mathrm{HbF}$ stain. P values were calculated using two-tailed Student's t-test. CD71 = anti-transferrin receptor; $\mathrm{GPA}=$ anti-glycophorin $\mathrm{A} ; \mathrm{TO}=$ thiazole orange; $\mathrm{HbF}=$ fetal hemoglobin; $\mathrm{C}=$ control (negative control vector) transduction; $7 \mathrm{a}-\mathrm{TuD}=$ let-7a tough decoy design. ${ }^{*} p<0.05$

\section{Abbreviations}

BCL11A: B-cell CLL/lymphoma 11A gene; BCL11A-KD: BCL11A knockdown; CA1: carbonic anhydrase I gene; CDNA: complementary DNA; CD71: transferrin receptor; Copies/ng cDNA: copy number per nanogram cDNA; GCNT2: glucosaminyl (N-acetyl) transferase 2 gene; GPA: glycophorin A; HbF: fetal hemoglobin; HMGA2: high mobility group AT-hook 2 gene; HPLC: high-performance liquid chromatography; KLF1: Kruppel like factor 1 gene; Let-7a-TuD: let-7a tough decoy design; Let-7b-TuD: let-7b tough decoy design; LIN28A: lin-28 homolog A gene; LIN28B: lin-28 homolog B gene; miRNAs: microRNAs; mRNAs: messenger RNAs; RT-qPCR: quantitative reverse-transcriptase polymerase chain reaction; SOX6: SRY-box 6 gene; TO: thiazole orange; TuD: tough decoy; ZBTB7A: zinc finger and BTB domain containing 7A gene.

\section{Authors' contributions}

JFV designed, performed, and analyzed experiments, and wrote the paper. CB, YTL, JMA and MK performed and analyzed experiments. AR conducted clinical research. JLM conceived, assisted, and directed the research, and wrote the paper. All authors read and approved the final manuscript.

\section{Acknowledgements}

We would like to thank the Department of Transfusion Medicine for their expertise in obtaining CD34(+) cells.

\section{Competing interests}

The authors declare that they have no competing interests.

\section{Availability of data and materials}

All data generated or analyzed during this study are included in this published article and its Additional files 1, 2, 3. 


\section{Consent for publication}

Not applicable.

\section{Ethics approval and consent to participate}

Written informed consent was obtained from all research subjects prior to participation in this study. Approval for the research protocol and consent documents using primary erythroblasts and peripheral blood samples was granted by the Intramural National Institute of Diabetes and Digestive and Kidney Diseases Institutional Review Board.

\section{Funding}

The Intramural Research Program of the National Institute of Diabetes and Digestive and Kidney Diseases supported this work.

\section{Publisher's Note}

Springer Nature remains neutral with regard to jurisdictional claims in published maps and institutional affiliations.

Received: 3 February 2017 Accepted: 26 July 2017

Published online: 02 August 2017

\section{References}

1. Krol J, Loedige I, Filipowicz W. The widespread regulation of microRNA biogenesis, function and decay. Nat Rev Genet. 2010;11:597.

2. Roush S, Slack FJ. The let-7 family of microRNAs. Trends Cell Biol. 2008;18:505-16

3. Viswanathan SR, Daley GQ. Lin28: a microRNA regulator with a macro role. Cell. 2010;140:445-9.

4. Ong KK, Elks CE, Li S, Zhao JH, Luan J, Andersen LB, Bingham SA, Brage S, Smith GD, Ekelund U, et al. Genetic variation in LIN28B is associated with the timing of puberty. Nat Genet. 2009;41:729-33.

5. He C, Kraft P, Chen C, Buring JE, Pare G, Hankinson SE, Chanock SJ, Ridker PM, Hunter DJ, Chasman DI. Genome-wide association studies identify loci associated with age at menarche and age at natural menopause. Nat Genet. 2009:41:724-8.

6. Lettre G, Jackson AU, Gieger C, Schumacher FR, Berndt SI, Sanna S, Eyheramendy S, Voight BF, Butler JL, Guiducci C, et al. Identification of ten loci associated with height highlights new biological pathways in human growth. Nat Genet. 2008;40:584-91.

7. Sulem P, Gudbjartsson DF, Rafnar T, Holm H, Olafsdottir EJ, Olafsdottir GH, Jonsson T, Alexandersen P, Feenstra B, Boyd HA, et al. Genome-wide association study identifies sequence variants on $6 \mathrm{q} 21$ associated with age at menarche. Nat Genet. 2009;41:734-8.

8. Polesskaya A, Cuvellier S, Naguibneva I, Duquet A, Moss EG, Harel-Bellan A. Lin-28 binds IGF-2 mRNA and participates in skeletal myogenesis by increasing translation efficiency. Genes Dev. 2007;21:1125-38.

9. Yu J, Vodyanik MA, Smuga-Otto K, Antosiewicz-Bourget J, Frane JL, Tian S, Nie J, Jonsdottir GA, Ruotti V, Stewart R, et al. Induced pluripotent stem cell lines derived from human somatic cells. Science. 2007;318:1917-20.

10. Noh SJ, Miller SH, Lee YT, Goh SH, Marincola FM, Stroncek DF, Reed C, Wang E, Miller JL. Let-7 microRNAs are developmentally regulated in circulating human erythroid cells. J Transl Med. 2009;7:98.

11. Lee YT, de Vasconcellos JF, Yuan J, Byrnes C, Noh SJ, Meier ER, Kim KS, Rabel A, Kaushal M, Muljo SA, Miller JL. LIN28B-mediated expression of fetal hemoglobin and production of fetal-like erythrocytes from adult human erythroblasts ex vivo. Blood. 2013;122:1034-41.

12. de Vasconcellos JF, Fasano RM, Lee YT, Kaushal M, Byrnes C, Meier ER, Anderson M, Rabel A, Braylan R, Stroncek DF, Miller JL. LIN28A expression reduces sickling of cultured human erythrocytes. PLoS ONE. 2014;9:e106924

13. Griffiths-Jones $S$. The microRNA registry. Nucleic Acids Res. 2004:32:D109-11.

14. Griffiths-Jones S, Grocock RJ, van Dongen S, Bateman A, Enright AJ. miRBase: microRNA sequences, targets and gene nomenclature. Nucleic Acids Res. 2006;34:D140-4.

15. Griffiths-Jones S, Saini HK, van Dongen S, Enright AJ. miRBase: tools for microRNA genomics. Nucleic Acids Res. 2008;36:D154-8.
16. Kozomara A, Griffiths-Jones S. miRBase: integrating microRNA annotation and deep-sequencing data. Nucleic Acids Res. 2011;39:D152-7.

17. Kozomara A, Griffiths-Jones S. miRBase: annotating high confidence microRNAs using deep sequencing data. Nucleic Acids Res. 2014;42:D68-73.

18. Lee YT, de Vasconcellos JF, Byrnes C, Kaushal M, Rabel A, Tumburu L, Allwardt JM, Miller JL. Erythroid-specific expression of LIN28A is sufficient for robust gamma-globin gene and protein expression in adult erythroblasts. PLoS ONE. 2015;10:e0144977.

19. Haraguchi T, Ozaki Y, Iba H. Vectors expressing efficient RNA decoys achieve the long-term suppression of specific microRNA activity in mammalian cells. Nucleic Acids Res. 2009;37:e43.

20. Tanno T, Porayette P, Sripichai O, Noh SJ, Byrnes C, Bhupatiraju A, Lee YT, Goodnough JB, Harandi O, Ganz T, et al. Identification of TWSG1 as a second novel erythroid regulator of hepcidin expression in murine and human cells. Blood. 2009;114:181-6.

21. Krivega I, Byrnes C, de Vasconcellos JF, Lee YT, Kaushal M, Dean A, Miller JL. Inhibition of G9a methyltransferase stimulates fetal hemoglobin production by facilitating LCR/gamma-globin looping. Blood. 2015;126:665-72.

22. de Vasconcellos JF, Lee YT, Byrnes C, Tumburu L, Rabel A, Miller JL. HMGA2 moderately increases fetal hemoglobin expression in human adult erythroblasts. PLoS ONE. 2016;11:e0166928.

23. Wojda U, Noel P, Miller JL. Fetal and adult hemoglobin production during adult erythropoiesis: coordinate expression correlates with cell proliferation. Blood. 2002;99:3005-13.

24. Sripichai O, Kiefer CM, Bhanu NV, Tanno T, Noh SJ, Goh SH, Russell JE, Rognerud CL, Ou CN, Oneal PA, et al. Cytokine-mediated increases in fetal hemoglobin are associated with globin gene histone modification and transcription factor reprogramming. Blood. 2009;114:2299-306.

25. Goh SH, Lee YT, Bhanu NV, Cam MC, Desper R, Martin BM, Moharram R, Gherman RB, Miller JL. A newly discovered human alpha-globin gene. Blood. 2005:106:1466-72.

26. Lee YT, Kim KS, Byrnes C, de Vasconcellos JF, Noh SJ, Rabel A, Meier ER, Miller JL. A synthetic model of human beta-thalassemia erythropoiesis using CD34+ cells from healthy adult donors. PLoS ONE. 2013:8:e68307.

27. Bak RO, Hollensen AK, Primo MN, Sorensen CD, Mikkelsen JG. Potent microRNA suppression by RNA Pol II-transcribed 'Tough Decoy' inhibitors. RNA. 2013:19:280-93.

28. Xie J, Ameres SL, Friedline R, Hung JH, Zhang Y, Xie Q, Zhong L, Su Q, He $R$, Li M, et al. Long-term, efficient inhibition of microRNA function in mice using rAAV vectors. Nat Methods. 2012;9:403-9.

29. Brady HJ, Edwards M, Linch DC, Knott L, Barlow JH, Butterworth PH. Expression of the human carbonic anhydrase I gene is activated late in fetal erythroid development and regulated by stage-specific trans-acting factors. Br J Haematol. 1990;76:135-42.

30. Piller F, Cartron JP, Maranduba A, Veyrieres A, Leroy Y, Fournet B. Biosynthesis of blood group I antigens. Identification of a UDP-GICNAc:GICNAC beta 1-3Gal(-R) beta 1-6(GlcNAc to Gal) N-acetylglucosaminyltransferase in hog gastric mucosa. J Biol Chem. 1984;259:13385-90.

31. Inaba N, Hiruma T, Togayachi A, Iwasaki H, Wang XH, Furukawa Y, Sumi R, Kudo T, Fujimura K, Iwai T, et al. A novel I-branching beta-1,6-Nacetylglucosaminyltransferase involved in human blood group I antigen expression. Blood. 2003;101:2870-6.

32. Sankaran VG, Menne TF, Xu J, Akie TE, Lettre G, Van Handel B, Mikkola HK, Hirschhorn JN, Cantor AB, Orkin SH. Human fetal hemoglobin expression is regulated by the developmental stage-specific repressor BCL11A. Science. 2008;322:1839-42.

33. Xu J, Peng C, Sankaran VG, Shao Z, Esrick EB, Chong BG, Ippolito GC, Fujiwara Y, Ebert BL, Tucker PW, Orkin SH. Correction of sickle cell disease in adult mice by interference with fetal hemoglobin silencing. Science. 2011;334:993-6.

34. Boyerinas B, Park SM, Shomron N, Hedegaard MM, Vinther J, Andersen JS, Feig C, Xu J, Burge CB, Peter ME. Identification of let-7-regulated oncofetal genes. Cancer Res. 2008:68:2587-91.

35. Masuda T, Wang X, Maeda M, Canver MC, Sher F, Funnell AP, Fisher C, Suciu M, Martyn GE, Norton LJ, et al. Transcription factors LRF and $B C L 11 \mathrm{~A}$ independently repress expression of fetal hemoglobin. Science. 2016:351:285-9. 
36. Zhou D, Liu K, Sun CW, Pawlik KM, Townes TM. KLF1 regulates BCL11A expression and gamma- to beta-globin gene switching. Nat Genet. 2010:42:742-4.

37. Xu J, Sankaran VG, Ni M, Menne TF, Puram RV, Kim W, Orkin SH. Transcriptional silencing of \{gamma\}-globin by BCL11A involves long-range interactions and cooperation with SOX6. Genes Dev. 2010;24:783-98.

38. Shell S, Park SM, Radjabi AR, Schickel R, Kistner EO, Jewell DA, Feig C, Lengyel E, Peter ME. Let-7 expression defines two differentiation stages of cancer. Proc Natl Acad Sci USA. 2007;104:11400-5.

39. Lee RC, Feinbaum RL, Ambros V. The C. elegans heterochronic gene lin-4 encodes small RNAs with antisense complementarity to lin-14. Cell. 1993;75:843-54

40. Wightman B, Ha I, Ruvkun G. Posttranscriptional regulation of the heterochronic gene lin-14 by lin-4 mediates temporal pattern formation in C. elegans. Cell. 1993;75:855-62.
41. Reinhart BJ, Slack FJ, Basson M, Pasquinelli AE, Bettinger JC, Rougvie AE, Horvitz HR, Ruvkun G. The 21-nucleotide let-7 RNA regulates developmental timing in Caenorhabditis elegans. Nature. 2000;403:901-6.

42. Pasquinelli AE, Reinhart BJ, Slack F, Martindale MQ, Kuroda MI, Maller B, Hayward DC, Ball EE, Degnan B, Muller P, et al. Conservation of the sequence and temporal expression of let-7 heterochronic regulatory RNA. Nature. 2000;408:86-9.

43. Mestdagh P, Hartmann N, Baeriswyl L, Andreasen D, Bernard N, Chen C, Cheo D, D'Andrade P, DeMayo M, Dennis L, et al. Evaluation of quantitative miRNA expression platforms in the microRNA quality control (miRQC) study. Nat Methods. 2014;11:809-15.

44. Piskounova E, Polytarchou C, Thornton JE, LaPierre RJ, Pothoulakis C, Hagan JP, Iliopoulos D, Gregory RI. Lin28A and Lin28B inhibit let-7 microRNA biogenesis by distinct mechanisms. Cell. 2011;147:1066-79.

\section{Submit your next manuscript to BioMed Central and we will help you at every step:}

- We accept pre-submission inquiries

- Our selector tool helps you to find the most relevant journal

- We provide round the clock customer support

- Convenient online submission

- Thorough peer review

- Inclusion in PubMed and all major indexing services

- Maximum visibility for your research

Submit your manuscript at www.biomedcentral com/submit 